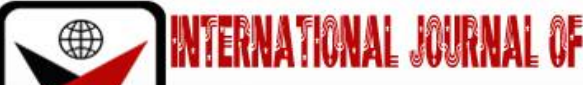

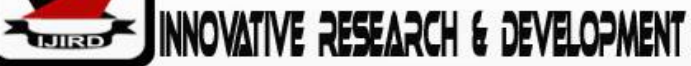

ISSN 2278 - 0211 (Online)

\section{Implementing Tik-Tok Game Cards to Reorient ESL Learners' Temporal Preposition Acquisition}

\author{
William Hoi Theng Ann \\ Academic Teacher, Primary School in Malaysia, Malaysia \\ Dr. Nur Ehsan \\ Senior Lecturer, Faculty of Education, UKM, Malaysia
}

\begin{abstract}
:
English is one of the widely spoken languages in the world. The global language plays the role of a second language in Malaysia. It is a language that is widely spoken among communities after the Malay Language. Contrary to its status as the second language, there are cases where some of the learners in Malaysia still find difficulties in mastering the grammatical structures. Preposition is one of the crucial components in English syntax where it plays the role of bridging and governing a noun and pronoun. Preposition ranges from the aspect of direction, time and place. However, the prepositional usages are confusing especially for those ESL learners due to its polysemy nature. Thus, this study discusses the effects of game cards in improving ESL learners' temporal preposition acquisition. This study adapted a quasiexperimental design involving an intact classroom of 30 pupils of Year 6 (age 12) at a national-type (Chinese) primary school in a sub-urban area in Perak, Malaysia. The data were collected and were analyzed through the paired sample ttest to determine if the intervention was indeed effective in aiding the participants in the temporal preposition acquisition.
\end{abstract}

Keywords: ESL learners, Malaysia, temporal preposition, game card, acquisition

\section{Introduction}

The ultimate objective of the education system of Malaysia is to produce learners who are capable of mastering both Malay Language, the national language and English Language, the official and international language in Malaysia. In the context of Malaysia, English Language is positioned as the second language of the nation. Thus, the education system is tailored based on the education ministry's vision. Policies such as Highly Immersive Program (HIP) and Dual Language Program (DLP) are introduced for boosting the local English Language proficiency level.

English Language has started at the root level of education where in pre-schools, children are exposed with English alphabets and simple vocabulary. After proceeding to the level of lower primary school level, children are further exposed with basic sentence structures about English Language and its usage such as daily conversations along with syntactical knowledge of the language itself. Children are then exposed to higher structural level of the language such as paragraph constructing and short essay writing. Only then the children will be exposed with a much more complex level of English essay writing and text summarizing during secondary school level. Then, English Language will be widely used during tertiary education level in colleges and universities whereby most of the references, writings are in English Language. From the explanations above, it is not hard to see that, English Language is widely implemented in the nation's education system. Thus, it should be said that, Malaysian ESL learners are supposed to be proficient in the language itself, however, things do not seem developing towards the desired direction.

Malaysian ESL learners still face difficulties especially when it comes to grammatical sections of the language itself, especially preposition (Loi et.al 2017, Loke et.al 2013). Preposition is categorised among the main eight-word classes or be known as parts of speech alongside nouns, pronouns, verbs, determiners, adjectives, adverbs and conjunctions. Preposition plays its role as a connector and dictating a noun and pronoun in sentences. There are various types of prepositions that stretches to the aspect of time, direction, positions, places and degrees (Morenberg 1997; Mukundan 2009). Prepositions are rather unique compared to other grammatical word classes as the prepositions themselves are polysemy, or can be explained as words with many meanings in different contexts. They are short, yet, important enough to dictate the meaning of the sentence itself (Arjan et.al 2013). Among the factors that caused Malaysian learners to stumble when it comes to preposition learning are first language interferences, different prepositional usages across languages and the abstractness of the prepositions themselves (Loi et.al 2017, Loke et.al 2013, Saravanan 2015). Past studies suggest that interactive and unorthodox learning methods are indeed effective in helping the ESL students in English mastering. In the studies by Hang et.al (2017), participants are found to be more interested and learn better through the interactive language games. It was found that they were more engaged and focused in their learning when it comes to games rather than the orthodox methods of learning. 
Thus, interactive and effective interventions are required to curb the difficulties of preposition mastering among Malaysian learners. The aim of this study is to improve the acquisition of temporal prepositions among the participants through the implementation of the intervention, Tik-Tok game card. The improvements of participants after the implementation of the intervention shall be analyzed thoroughly in order to prove that there will be significant difference of results after the implementation of intervention.

\section{Literature Review}

Grammar is the governing system of conventional arrangement within a sentence. Thus, grammars are considered a vital element that must be mastered in order to be called as proficient in English Language. Researchers stated that grammars should be learned in a covert, meaningful manner especially for those non-native English speakers (Loewen 2005; Sudhakaran 2015). Being one of the word classes in English Language, preposition has a wide range of meanings that stretches into aspects like time, position, place, degrees and directions. The trait of preposition for bearing multiple meanings in a word is called polysemy.

However, the abstractness of the preposition itself proved to be an obstacle for non-native English speakers as they find it hard to grasp the meaning since the words are indescribable by using objects that can be seen. The prepositions are unable to be really seen, touched, or felt by our senses. Most of the prepositions deals with the user's imaginary perspective. Researchers in some past studies discuss a common trait that is shared by the non-native English speakers which is the difficulty to grasp the abstract meanings in English Language since the language itself is not their first language (Loi et.al 2017, Loke et. al 2013 and Saravanan 2015). The prepositions used in English such as "In", "On" and "At" that are being used in temporal preposition are hard to be comprehensible as the learners face hard times on figuring out the differences of the usages.

Besides that, the sharing of prepositional terms across different types of prepositions along with its nuances such as "In", "On" and "At" confuses the non-native English speakers. For instance, in the sentence "I will be at the canteen at 10.00 a.m." the preposition "At" appeared twice but both representing different context where one represents time, the other is referring to location. The crossover usage of prepositional terms confuses the ESL learners and the abstractness of the terms make the explanation to be even more difficult (Saravanan 2015).

Next, the interference of the first language poses another difficulty as the usage of prepositions are different across languages. ESL learners face difficulties during the process of code switching across languages (Saravanan 2015, Loi et. al 2017). Some prepositions in English Language does not exist in other languages or other languages might combine the usages of their own set of prepositions. For example, in Mandarin, temporal preposition is summarized as “在” which brings the meaning "At" in English language rather than being categorised as "In", "On", and "At". In Malay Language, the national and official language of Malaysia, shares the similar pattern of temporal preposition usage as the Mandarin's as the language too, uses "pada" which literally translated as "At" to sum up all the three temporal prepositions "In", "On", and "At".

Based on past studies, in the study done by Razali et.al (2017), the researchers chose language game card as their tool of study to improve social interaction sentences (social expressions) whereby it has been discovered that game cards creates mental linkages and vocabularies retention among the players and the players have shown visible improvements in post-test scores and were able to recall phrases of social interaction phrases even after a month after the card game implementation. Gaudart (1999), Müller et.al (2017) agree that language games ignite learners' interest in the process of learning a language where games provide specific and clear learning objectives for the players to achieve. The scholars stated that language games are indeed providing a specific platform for communication and learning with an added element of competitiveness in them.

The review of existing literature indicates that there is a need for the educators to tackle this problem of prepositions mastering by the ESL learners who speak Mandarin as their first language. Educators need to think of interactive and innovative ways such as language games to allow the learners to stay engaged in learning, while keeping them interested and providing them a simple and direct method to learn prepositions in English.

\section{Research Methodology}

\subsection{Research Design}

The research design that was implemented in this study is the Quasi-Experimental research design. Quasi experimental research design is mostly applied on situations where researchers are having intact groups in the research due to limitations under the factors such as participants' availability or restricted environmental settings (Creswell 2012, p.310). In this particular research design, random assignments of participants are not allowed, where participants are specifically selected groups. Through the paired sample T-test analysis, the data analyzed will be used as a measuring ruler to define the intervention's effectiveness. The rationale behind the researcher's selection of research design is due to the availability of participants. The researcher is currently teaching in a Chinese primary school as an English teacher. The research participants are originated from his class of 12 years old children (Year 6). The researcher would like to improve their mastery of temporal prepositions and simultaneously to identify if the study's intervention is indeed effective in improving their temporal preposition acquisition.

\subsection{Research Participants}

The research participants that that were included in this study is originated from a Chinese primary school in a sub-urban school in the state of Perak, Malaysia. For both the experimental and control group, the research participants in 
both classes are 12 years old (Year 6) and all of them are non-native English speakers where their mother tongues are Mandarin, Tamil and Malay Language. Their English level of competence can be summed as mixed abilities.

\subsection{Intervention Implementation Stage}

\begin{tabular}{|c|l|l|}
\hline Sessions & Activities & Rationale \\
\hline $\mathbf{1}$ & $\begin{array}{l}\text { Pre-test conducting } \\
\text { on the participants }\end{array}$ & $\begin{array}{l}\text { To identify participants' prior knowledge } \\
\text { regarding temporal preposition }\end{array}$ \\
\hline $\mathbf{2}$ & $\begin{array}{l}\text { Intensive temporal } \\
\text { preposition lesson } \\
\text { Tutorial of card } \\
\text { game flow. }\end{array}$ & $\begin{array}{l}\text { Explaining with the fundamental concepts } \\
\text { of temporal preposition }\end{array}$ \\
\hline $\mathbf{3}$ & $\begin{array}{l}\text { Explaining card game rules and the flow of } \\
\text { the game towards the participants } \\
\text { intervention } \\
\text { gameplay }\end{array}$ & $\begin{array}{l}\text { Participants undergo the intervention } \\
\text { under teacher's supervision. }\end{array}$ \\
\hline $\mathbf{4}$ & Post-test session & $\begin{array}{l}\text { Assess and identify if there are any } \\
\text { improvements among participants through } \\
\text { score comparisons of pre-tests and post- } \\
\text { tests. }\end{array}$ \\
\hline $\mathbf{5}$ & & \\
\hline
\end{tabular}

Table 1: Flow of card game Intervention

The table above has shown the cycle flow of the intervention implementation process. The intervention lasted for two weeks with a total of 30 hours and there were five main sessions in the cycle. In the first cycle, participants were given a set of pre-tests to be answered. The rationale of this was to identify the prior knowledge of the participants regarding the temporal preposition. The following session was the intensive temporal preposition lessons whereby the participants were exposed to the basic concepts of the preposition usage. The third session was the time where the participants were familiarized with the card game rules. The researcher explained the game flow and rules thoroughly to the participants. Subsequently after the third session, the card game intervention was implemented. The researcher, which is also the teacher of the participants shall be the game judge and supervisor. The researcher supervised the whole session of game play to avoid any foul playing and incorrect answering through card matching gameplay. Lastly, after went through all the sessions stated, the participants were provided with the post-test worksheet, the same set of questions as the pre-test to ensure questions reliability and validity. Scores of both tests were collected and analyzed through paired sample T-test to identify if the intervention did bring improvements on the acquisition of participants.

\subsection{Methods of Data Analysis}

The data analysis was firstly conducted through the comparison of the average mean score among the participants during the pre-test and post-test. This first stage results shall provide the researcher with brief visual scene for any improvements among the participants. Subsequently, paired sample T-test will be carried out to identify if the changes occurred in the results are indeed due to the influence of the intervention and not merely happening by chance. The combination of these two analyses will provide a clear insight for the researcher to suggest that the intervention is effective in aiding the acquisition among the participants.

\section{Result Analysis}

Within a span of 2 weeks, the intervention was implemented. The selected participants were given a pre-test at first and their scores were recorded. Following then, the participants from were called for intensive sessions whereby the rules of the card game and their temporal prepositions were being revised. The card game intervention was then being conducted to improve the acquisition of the participants on temporal prepositions. At the end of the phase, the post-test which is the exact copy of the pre-test were given and participants were required to answer the test. This is the way to identify if the card game intervention is indeed effective or ineffective in raising the acquisition of temporal prepositions among the participants. The rationale behind the usage of the same test paper as pre-test is to ensure the questions rubric's validity and reliability in the results obtained after being answered.

\begin{tabular}{|l|c|c|}
\hline School & $\begin{array}{l}\text { Pre-test score mean } \\
\text { (out of 20 questions) }\end{array}$ & $\begin{array}{c}\text { Post-test score mean } \\
\text { (out of 20 questions) }\end{array}$ \\
\hline Experimental group (30 pupils) & 7.97 & 12.40 \\
\hline
\end{tabular}

Table 2: Mean Scores Comparison Table between Pre-Test and Post-Test

As we may observe from the findings shown in the below tables (Table 3 and Table 4), the average score of the participants were at the level of 7.97 marks out of 20 marks with majority of them scored 8 marks only. (Mode) The situation shows that the mastery of temporal preposition among the participants are yet solid and there are a lot of mistakes in their test papers. Participants shown confusions among the usage of temporal prepositions "in", "on" and "at" as they were unable to identify the differences among them. This proved the statements by Loi et.al (2017), Loke et. al 
(2013) and Saravanan (2015). This is mainly due to the uniformed and combined usage of temporal prepositions in their respective mother tongues whereby the usage of "at" covers all of the aspects and time frames in temporal prepositions.

\begin{tabular}{|c|c|c|}
\hline \multicolumn{3}{|c|}{ Statistics } \\
\hline \multicolumn{2}{|c|}{ Pre-Test scores } \\
\hline \multirow{2}{*}{$\mathrm{N}$} & Valid & 30 \\
\cline { 2 - 3 } & Missing & 0 \\
\hline Mean & 7.9667 \\
\hline Median & 8.0000 \\
\hline Mode & 8.00 \\
\hline Std. Deviation & 3.09040 \\
\hline Variance & 9.551 \\
\hline Sum & 239.00 \\
\hline
\end{tabular}

Table 3: SPSS Central Tendency Descriptive Statistic Calculation Table

\begin{tabular}{|l|l|r|r|r|r|}
\hline \multicolumn{2}{|c|}{ Pre-test } \\
\hline \multirow{3}{*}{} & Frequency & Percent & Valid Percent & $\begin{array}{c}\text { Cumulative } \\
\text { Percent }\end{array}$ \\
\hline \multirow{6}{*}{ Valid } & 2.00 & 1 & 3.3 & 3.3 & 3.3 \\
\cline { 2 - 6 } & 4.00 & 3 & 10.0 & 10.0 & 13.3 \\
\cline { 2 - 6 } & 5.00 & 3 & 10.0 & 10.0 & 23.3 \\
\cline { 2 - 6 } & 6.00 & 3 & 10.0 & 10.0 & 33.3 \\
\cline { 2 - 6 } & 7.00 & 3 & 10.0 & 10.0 & 43.3 \\
\cline { 2 - 6 } & 8.00 & 6 & 20.0 & 20.0 & 63.3 \\
\cline { 2 - 6 } & 9.00 & 3 & 10.0 & 10.0 & 73.3 \\
\cline { 2 - 6 } & 10.00 & 2 & 6.7 & 6.7 & 80.0 \\
\cline { 2 - 6 } & 11.00 & 1 & 3.3 & 3.3 & 83.3 \\
\cline { 2 - 6 } & 12.00 & 2 & 6.7 & 6.7 & 90.0 \\
\cline { 2 - 6 } & 13.00 & 2 & 6.7 & 6.7 & 96.7 \\
\cline { 2 - 6 } & 15.00 & 1 & 3.3 & 3.3 & 100.0 \\
\cline { 2 - 6 } & Total & 30 & 100.0 & 100.0 & \\
\hline
\end{tabular}

Table 4: Pre-test Scores Analysis Table

Based on the frequency table shown (Table 4), the participants, initially showed poor performances. The below par performance shows that one of them even obtained 2 marks only, thus showing a poor mastery of temporal preposition. On average, the participants did not show a good average result.

However, the results showed improvements after the implementation of post-test. The analysis table shown below (Table 5 and Table 6) has an average score of the participants after the implementation of the card game. It has shown an increment from 7.97 marks to a score of 12.40 marks on average. The difference between the mean score is 4.43 marks. The mode of the scores has also increased from 8 marks to 10 marks. In the frequency table of the post-test, the lowest score shown has gone from 2 marks to now 6 marks.

\begin{tabular}{|c|c|c|}
\hline \multicolumn{3}{|c|}{ Statistics } \\
\hline \multicolumn{3}{|c|}{ Post-Test Scores } \\
\hline \multirow[t]{2}{*}{$\mathrm{N}$} & Valid & 30 \\
\hline & Missing & 0 \\
\hline \multicolumn{2}{|c|}{ Mean } & 12.4000 \\
\hline \multicolumn{2}{|c|}{ Median } & 12.0000 \\
\hline \multicolumn{2}{|c|}{ Mode } & $10.00^{\mathrm{a}}$ \\
\hline \multicolumn{2}{|c|}{ Std. Deviation } & 2.79901 \\
\hline \multicolumn{2}{|c|}{ Variance } & 7.834 \\
\hline \multicolumn{2}{|c|}{ Sum } & 372.00 \\
\hline
\end{tabular}

Table 5: SPSS Central Tendency Descriptive Statistic Calculation Table 


\begin{tabular}{|c|c|c|c|c|c|}
\hline \multicolumn{9}{|c|}{ Post test } \\
\hline \multirow{3}{*}{ Valid } & Frequency & Percent & Valid Percent & Cumulative Percent \\
\cline { 2 - 6 } & 8.00 & 1 & 3.3 & 3.3 & 3.3 \\
\cline { 2 - 6 } & 9.00 & 1 & 3.3 & 3.3 & 6.7 \\
\cline { 2 - 6 } & 9.00 & 1 & 3.3 & 3.3 & 10.0 \\
\cline { 2 - 6 } & 10.00 & 5 & 16.7 & 16.7 & 26.7 \\
\cline { 2 - 6 } & 11.00 & 5 & 16.7 & 16.7 & 43.3 \\
\cline { 2 - 6 } & 12.00 & 4 & 13.3 & 13.3 & 56.7 \\
\cline { 2 - 6 } & 13.00 & 1 & 3.3 & 3.3 & 60.0 \\
\cline { 2 - 6 } & 14.00 & 5 & 16.7 & 16.7 & 76.7 \\
\cline { 2 - 6 } & 15.00 & 1 & 3.3 & 3.3 & 80.0 \\
\cline { 2 - 6 } & 16.00 & 5 & 16.7 & 16.7 & 96.7 \\
\cline { 2 - 6 } & 18.00 & 1 & 3.3 & 3.3 & 100.0 \\
\cline { 2 - 6 } & Total & 30 & 100.0 & 100.0 & \\
\hline
\end{tabular}

Table 6: Post-test scores Analysis Table

From both the mean calculation comparison, it is visible that, during the post-intervention phase, the participants performed better in their post-test. This can be visible in their increase of average marks across all the participants in experimental group.

In order to ensure further that participants are indeed showing improvements after the implementation of intervention, a paired sample T-test was conducted to prove the effectiveness of intervention. Prior to the paired T-test calculation, assumptions of T-tests should be met. Based on the normality test results below, the researcher selected Shapiro-Wilk test to be analyzed.

\begin{tabular}{|c|c|c|c|c|c|c|}
\hline \multicolumn{7}{|c|}{ Tests of Normality } \\
\hline & \multicolumn{3}{|c|}{ Kolmogorov-Smirnov } & \multicolumn{3}{c|}{ Shapiro-Wilk } \\
\cline { 2 - 7 } & Statistic & df & Sig. & Statistic & df & Sig. \\
\hline Pre_Test & .129 & 30 & $.200^{*}$ & .974 & 30 & .661 \\
\hline Post_test & .125 & 30 & $.200^{*}$ & .965 & 30 & .405 \\
\hline
\end{tabular}

Table 7: Data Normality Tests

In table 7 , the $p$-value (sig) for both tests are 0.661 and 0.405 respectively, with both figures exceeding the alpha value of 0.05 , thus showing that the two sets of tests results are indeed showcasing normally distributed sets of data. Subsequently, paired sample T-test was carried out after all the T-test assumptions have been met. The pre-test and posttest results were brought into analysis and the outcome was portrayed in the table below (Table 8).

\begin{tabular}{|c|c|c|c|c|c|c|c|c|c|}
\hline \multicolumn{10}{|c|}{ Paired Samples Test } \\
\hline & & \multicolumn{5}{|c|}{ Paired Differences } & \multirow[t]{3}{*}{$\mathrm{t}$} & \multirow[t]{3}{*}{ df } & \multirow{3}{*}{$\begin{array}{c}\text { Sig. } \\
\text { (2-tailed) }\end{array}$} \\
\hline & & \multirow[t]{2}{*}{ Mean } & \multirow{2}{*}{$\begin{array}{c}\text { Std. } \\
\text { Deviatio } \\
\mathrm{n}\end{array}$} & \multirow[t]{2}{*}{$\begin{array}{l}\text { Std. Error } \\
\text { Mean }\end{array}$} & \multicolumn{2}{|c|}{$\begin{array}{l}\text { 95\% Confidence Interval } \\
\text { of the Difference }\end{array}$} & & & \\
\hline & & & & & Lower & Upper & & & \\
\hline Pair 1 & $\begin{array}{l}\text { Pre_Test- } \\
\text { Post_test }\end{array}$ & $\begin{array}{c}- \\
4.43333\end{array}$ & .77385 & .14129 & -4.72230 & -4.14437 & $\begin{array}{c}- \\
31.378\end{array}$ & 29 & .000 \\
\hline
\end{tabular}

Table 8: Paired sample T-tests results

In the above table (Table 8), the $p$-value (sig 2-tailed) shows a figure of 0.000 , a figure that is lesser than 0.05 . Thus, it can be concluded that the intervention (card game) brings positive impact and improve the study participants' temporal preposition acquisition and these changes are not occurred by chance.

\subsection{Discussion of Findings}

The results presented in Test-score analysis tables (Table 3 and Table 5) and the paired sample T-tests (Table 8) has suffice the claim that the game card is indeed an effective intervention that aids the temporal preposition acquisition. The results have proven the null hypothesis of stating that the intervention did not bring any significant difference towards the acquisition wrong.

As an overall, it may be said that, based on all the data analysis above, the study is indeed successful and proved that the implementation of card game really does aid the acquisition of participants in temporal preposition. The interactive manner and engaging trait of the game really has had a positive effect on their temporal preposition acquisition on long term. This has proved the point of the study by Gaudart (1999) that games are indeed effective in teaching a language as it is interactive and attracting learners' attention. 


\section{Summary and Conclusion}

In the process of mastering English Language, the prepositional usage often caused continuing problems for nonnative English speakers such as first language interference and the nuances and the abstractness of the prepositions. Thus, interactive and effective methods have to be developed in order to help the ESL learners to learn prepositions in a more effective and interactive manner.

As a summary, this study has examined the effectiveness of the card game intervention as a method of aiding the participants to master temporal preposition "in", "on" and "at". The results have portrayed that the achievements of the participants have shown tremendous improvements based on the average score from 7.97 to 12.40. The lowest score of the participants grew from 2 marks to 6 marks. The results have answered the research question of the study of identifying if the card game intervention is indeed effective in aiding the participants in temporal preposition acquisition where it is indeed indicating its effectiveness in curbing the problem of ESL students who are having hard times in mastering English Language prepositions. The study's hypothesis whereby significant improvements shall be observed after the implementation of intervention has been suggested to be improving the situation.

Although the present study is limited to examining learning achievement of temporal prepositions "in", "on", and "at", it may extend its way for future research on similar domains such the inclusion of more prepositions, phrases and types of prepositions such as preposition of place and positions. It may as well to be conducted on a larger scale with a larger study sample that includes a wider area of conduction.

\section{References}

i. Arjan, A., Abdullah, N. H., \& Roslim, N. (2013). A corpus-based study on english prepositions of place, in and on. English Language Teaching, 6(12), 167-174. https://doi.org/10.5539/elt.v6n12p167

ii. Creswell, John. W. 2012. Educational Research: planning, conducting, and evaluating quantitative and qualitative research/John

iii. W. Creswell. - $4^{\text {th }}$ ed, Nebraska. Pearson Publishing Ltd.

iv. Gaudart, H. (1999). Games as Teaching Tools for Teaching English to Speakers of Other Languages, 30(3), 283291.

v. Hang, S., \& Brussel, V. U. (2017). Using Games to teach Young Children English Language, (August).

vi. Kim, Loi. C., Akkakoson, S., Odacıoğlu, M. C., Suki, N. M., \& Bating, H. (2017). Malay ESL Students' Difficulties in Using English Prepositions. International Journal of Languages, Literature and Linguistics, 3(3), 122-127. https://doi.org/10.18178/IJLLL.2017.3.3.121

vii. Loke, D. L., Ali, J., \& Norain Zulkifli Anthony, N. (2013). A corpus based study on the use of preposition of time "on" and "at" in argumentative essays of form 4 and form 5 Malaysian students. English Language Teaching, 6(9), 128135. https://doi.org/10.5539/elt.v6n9p128

viii. Mukundan, Jayaran and Halim, N. (2009). Textbook representation of prepositions. English Language Teaching, 2(4), 13-24.

ix. Mueller, C. M. (2011). English learners' knowledge of prepositions : Collocational knowledge or knowledge based on meaning ? System, 39(4), 480-490. https://doi.org/10.1016/j.system.2011.10.012

X. Razali, W. N., Amin, N. M., Kudus, N. V., \& Musa, M. K. (2017). Using Card Game to Improve Vocabulary Retention : A Preliminary Study, 3(1), 30-36.

xi. Saravanan, J. (2015). The Use of English Prepositions : An Empirical Study. Journal of NELTA, 19(1), 158-168. https://doi.org/10.3126/nelta.v19i1-2.12089

xii. Sudhakaran, B., \& Jaya, P. (2015). Acquisition of English Prepositions among Malaysian Learners : A Case Study, 5(3), 1-10. https://doi.org/10.5539/ijel.v5n3p1 